\title{
IL-6 serum levels predict postoperative morbidity in gastric cancer patients
}

\author{
Antoni M. Szczepanik • Lucyna Scislo • Thecla Scully • Elzbieta Walewska • \\ Maciej Siedlar · Piotr Kolodziejczyk • Marzena Lenart • Magdalena Rutkowska • \\ Aleksander Galas $\cdot$ Antoni Czupryna $\cdot$ Jan Kulig
}

Received: 21 July 2010/Accepted: 21 February 2011/Published online: 20 April 2011

(c) The Author(s) 2011. This article is published with open access at Springerlink.com

\begin{abstract}
Background Despite progress in surgical techniques and perioperative care, gastrectomy remains a procedure of significant morbidity. Several scoring systems and clinical measures have been adopted to predict postoperative complications in gastric cancer patients. The aim of this study was to investigate whether high serum levels of interleukin 6 (IL-6) in the early postoperative period may be a prognostic factor of postoperative morbidity.

Methods A group of 99 consecutive patients with resectable gastric cancer were enrolled. The mean age was 62.9 years and the male/female ratio was 72:27. Subtotal gastric resection was performed in 22 patients and total
\end{abstract}

A. M. Szczepanik $(\bowtie) \cdot$ P. Kolodziejczyk · A. Czupryna .

J. Kulig

1st Department of General and Gastrointestinal Surgery,

Jagiellonian University Medical College, 40 Kopernika Str,

31-501 Kraków, Poland

e-mail: msszczep@cyf-kr.edu.pl

L. Scislo $\cdot$ E. Walewska

Department of Clinical Nursing, Faculty of Health Sciences, Institute of Nursing and Midwifery, Jagiellonian University,

Kraków, Poland

M. Siedlar · M. Lenart · M. Rutkowska

Department of Clinical Immunology Polish-American, Institute of Pediatrics, Jagiellonian University Medical College,

Kraków, Poland

T. Scully

Intensive Care Unit, Eastbourne District General Hospital, East Sussex, UK

A. Galas

Chair of Epidemiology and Preventive Medicine,

Jagiellonian University Medical College, Kraków, Poland gastric resection in 77. The IL-6 serum level was measured on the 1st postoperative day (POD).

Results Complications were recorded in 28 patients (28.3\%). The observed case-fatality rate was 3.03\%. An IL-6 serum level of $>288.7 \mathrm{pg} / \mathrm{ml}$ on the 1st POD in univariate and multivariate Cox proportional hazard models was an independent prognostic factor for overall complications and infective complications.

Conclusion Our study showed an association between perioperative IL-6 serum levels and postoperative morbidity in gastric cancer patients. The IL-6 serum level on the 1st POD was shown to be an independent prognostic factor for both overall complications and infective complications.

Keywords Gastric cancer · Postoperative morbidity · Interleukin 6

\section{Introduction}

Postoperative morbidity affects the overall survival, postoperative mortality, length of hospital stay, and cost of treatment involved in every major surgical procedure. In gastric cancer surgery postoperative morbidity remains high and even if the incidence of gastric cancer declines in the future this is likely to remain a problem [1]. It is therefore crucial for both the patient and surgeon to have a reliable risk assessment model for each major surgical procedure. For this reason the number of scoring systems involved in preoperative risk assessment has become increasingly tailored to specific groups of patients $[2,3]$.

Scoring systems predict risk and lead to the implementation of both prophylactic measures and appropriate perioperative treatment plans. In the case of gastric cancer, 
primarily a surgical disease, the group of patients disqualified from surgery due to unacceptably high preoperative risk is marginal. Moreover, some risk factors or risk-generating events are intraoperative. Therefore, a need has arisen for additional markers or measures that reflect operative injury.

Acute phase proteins (APPs) are defined as those proteins whose serum concentrations increase or decrease by at least $25 \%$ during inflammatory or post-injury states [4]. Changes in levels of APPs result from the effects of inflammatory mediators, mainly cytokines. Some of the major cytokines relevant to the acute phase response are interleukin (IL)-6, IL-1 beta, tumor necrosis factor-alpha $(\mathrm{TNF}-\alpha)$ and interferon gamma. These proteins stimulate APP production, with IL- 6 being the major inducer of most APPs [5]. This family of cytokines also suppresses the synthesis of albumin by the liver [6]. On the other hand, some cytokines (IL-10 and IL-4) suppress the inflammatory reaction. In addition to changes in the levels of APPs, a number of behavioral, physiologic, biochemical, and nutritional changes are induced by inflammation-associated cytokines. These include: fever [7]; neuroendocrine system effects, such as increased production of corticotropin-releasing hormone [8]; and anemia of chronic disease [9]. Cytokines, especially IL-6, are also known to correlate with operative stress and in some surgical procedures cytokines have been shown to be reliable markers of postoperative morbidity [10]. IL-6 is a cytokine whose levels rise very early post-surgery [11].

The aim of this study was to investigate whether high serum levels of IL-6 in the early postoperative period may be a prognostic factor of postoperative morbidity.

\section{Methods}

A group of 99 consecutive patients with resectable gastric cancer were enrolled in the study between n March 2005 and September 2006. This study was a cohort study in which gastric cancer patients were followed up for postoperative complications.

For the purpose of the study two groups of patients were created in the post-hoc analysis. Those whose serum IL-6 level was over the 90th percentile in the whole study group on the 1st postoperative day (POD) were defined as the "high IL-6 level" group, and those whose level was below the value mentioned were defined as the "low IL-6 level" group.

The cutoff level was arbitrally set because there are no data in the literature that indicate specific cutoff values or allow the creation of "high level" or "low level" groups in the postoperative period.
There were 27 women and 72 men in our cohort, and the mean age was 62.9 years (SD 11.2), with ages ranging between 33 and 86 years. None of the patients selected underwent preoperative chemotherapy and none had active infection. All patients were treated with standard postoperative care, including enteral nutrition, antimicrobial prophylaxis for up to $48 \mathrm{~h}$ post-surgery, and low-molecular-weight heparin (LMWH). All complications associated with each patient were recorded daily, up to the day of discharge, and thereafter weekly for up to 14 days. Major and minor complications were integrated in the analysis. The case-fatality rate was observed up to 30 days. The average hospital stay was 13.7 days. Tumor staging was assessed according to the International Union Against Cancer (UICC) TNM classification, 7th edition. The details of clinicopathological status are summarized in Table 1 .

Standard lymphadenectomy for R0 and R1 resections was D2. In all cases of palliative resections the extent of lymphadenectomy was at least D1 (11 patients).

Table 1 Patients' characteristics

\begin{tabular}{ll}
\hline & $N=99$ \\
\hline Gender $(n, \%)$ & \\
Women & $27(27.3 \%)$ \\
Men & $72(72.7 \%)$ \\
Age (years) & \\
Mean (SD) & $62.9(11.2)$ \\
Min-max & $33-86$ \\
Stage $(n, \%)$ & \\
I & $8(8.1 \%)$ \\
II & $22(22.2 \%)$ \\
III & $23(23.2 \%)$ \\
IV & $46(46.5 \%)$ \\
\hline & $N=97$ \\
\hline Lauren classification $(n, \%)$ & \\
Intestinal $(1)$ & $36(37.1 \%)$ \\
Diffuse $(2)$ & $60(60.6 \%)$ \\
Not classified & $1(1.0 \%)$ \\
Type of surgery $(n, \%)$ & \\
Subtotal resection & $22(22.2 \%)$ \\
Total resection & $77(77.8 \%)$ \\
Tumor location $(n, \%)$ & $27(27.3 \%)$ \\
Cardia & $72(72.7 \%)$ \\
Other locations & \\
Resection radicality $(n, \%)$ & $42(42.4 \%)$ \\
R0 & $11(11.1 \%)$ \\
R1 & \\
R2 & \\
\hline & \\
& \\
\hline
\end{tabular}


Nutritional status was assessed. As the measures of malnutrition, total albumin level (cutoff $<3.5 \mathrm{~g} / \mathrm{dl}$ ), lymphocyte count (cutoff $<1500 / \mathrm{mm}^{3}$ ), and weight loss greater than $10 \%$ of body weight during 6 months were adopted. Patients were diagnosed as malnourished if two of these variables were observed.

Concomitant diseases were recorded. Cardiovascular diseases were observed in 49 patients, respiratory diseases in 7 patients, diabetes mellitus in 8 patients, and other chronic comorbidities in 10 patients.

The study was approved by the Institutional Ethics Commission (Approval number KBET/91/L/2004).

\section{Cytokine assay}

Blood samples were collected $16-20 \mathrm{~h}$ post closure of the wound. The blood was centrifuged and serum samples were stored at $-55^{\circ} \mathrm{C}$.

For the IL-6 assay the following monoclonal antibodies were used: IL-6 clone MQ2-13A5 (Capture) and MQ239C3 (Detection); Antibodies were diluted in $0.1 \mathrm{~mol}$ phosphate buffer, $\mathrm{pH}$ 9.0, and placed on a 96-well microplate (Nunc Maxisorb, Roskilde, Denmark) according to the manufacturer's instructions. The reaction was developed with biotinylated anti-mouse antibodies. The results were read using an enzyme-linked immunosorbent assay (ELISA) microplate reader (Universal Microplate Reader; Bio-Tek Instruments, Winooski, VT, USA) at the wavelength of $490 / 630 \mathrm{~nm}$. The detection range was $10-4030 \mathrm{pg} / \mathrm{ml}$.

\section{Record of complications}

The postoperative course was monitored, and all adverse events were recorded and analyzed. The complication rate was based upon clinical assessment, imaging studies, and microbiological examination. Complications were stratified into five groups:

- Infective complications (pneumonia, urinary tract infections, catheter-related infections, superficial wound infections)

- Surgical complications (anastomotic/duodenal stump leakage, intraabdominal bleeding, pancreatic fistula, wound dehiscence, intestinal obstruction, delayed wound healing)

- Respiratory complications (pulmonary embolism and respiratory insufficiency, not including pneumonia)

- Cardio-circulatory complications

- Other complications (gastrointestinal [GI] bleeding, transient pyrexia with negative bacterial cultures and without clinical signs of infection)
Statistical analysis

The proportion of patients without complications was presented using Kaplan-Meier curves and the difference between curves was tested using the log rank test.

To define patients with "high" IL-6 levels the cutoff was set at the 90th percentile.

For assessment of the risk of complications the Cox proportional hazard model was used.

For multivariate analysis, the following covariates were used: age $(\leq 50,51-60,61-70,>70$ years), stage (I-IV), Lauren's type, type of surgery (total or partial resection), resection radicality, nutritional status, and additionally: diagnosis of cardiovascular disease (yes/no), diagnosis of pulmonary disease (yes/no), diagnosis of diabetes (yes/no), and diagnosis of any other disease (yes/no).

A $p$ level of $<0.05$ was considered statistically significant. Statistical analysis was performed using the STATA v.8 (StataCorpLP, College Station, TX, USA) software package.

\section{Results}

The number of events and the type of complications were recorded for each patient. Because one patient could have more than one complication, the sum of complications (sum of events) exceeded the number of patients with complications.

Complications were observed in 28 of the 99 patients (28.3\%) and the observed sum of events was 68 (Table 2).

The most frequent group of complications were infections, diagnosed in $24.2 \%$ of the patients. In this group the main complication was hospital-acquired pneumonia (HAP). Among 9 surgical complications there was one case of anastomotic dehiscence. The perioperative case-fatality rate was 3.03\%-3 patients. These patients died on PODs 8,14 , and 27. All of these patients had been diagnosed with HAP on PODs four to seven and had no major surgical complications.

Table 2 Types of complications

\begin{tabular}{lc}
\hline Complication type & $N(\%)$ \\
\hline Infective & $24(24.2)$ \\
Pneumonia & $20(20.2)$ \\
Surgical & $9(9.1)$ \\
Respiratory (without pneumonia) & $5(5.1)$ \\
Cardio-circulatory & $4(4.0)$ \\
Other & $6(6.1)$ \\
\hline
\end{tabular}


IL-6 as a predictor of complications

The 1st POD serum level of IL-6 was analyzed as it was the earliest postoperative measure available, reflecting not only preoperative factors but also operative injury.

To assess the predictive value of IL- 6 serum levels on the 1st POD a cutoff level of $288.7 \mathrm{pg} / \mathrm{ml}$ (the equivalent of the 90th percentile) was set. Overall complications, including infective complications, were analyzed 14 days post-surgery. The proportion of patients without complications was significantly higher in patients with IL-6 levels below the cutoff value $(p=0.035)$, and the results were statistically significant (Fig. 1).

The hazard ratio (HR) of complication as an event assessed in the univariate Cox proportional hazard model was significantly higher in patients with "high" IL-6 levels in comparison to those with "low" IL-6 levels (HR $=2.40$, 95\% confidence interval [CI] 1.05-5.48)-Table 3. The multivariate analysis produced similar results $(\mathrm{HR}=2.79$, 95\% CI 1.01-7.76) and if the presence of the diagnosis of other chronic disease was taken into account the risk estimation was even higher (Table 3).

IL-6 on the 1st POD was also analyzed as a potential predictor of infective complications. The analysis of Kaplan-Meier curves for the proportion of patients without infective complications over 14 postoperative days revealed a trend similar to that seen with overall complications (Fig. 2). Moreover, these findings were confirmed by the univariate and multivariate Cox proportional hazard models (Table 4).

To avoid the confounding effect of surgical radicality, another model, with classification $R(0,1,2)$ as one of possible

Cumulative proportion of patients without complications

(Kaplan - Meyer plots; log rank test $\mathrm{p}=0.035$ )

o Completed $\because$ Censored — normal IL6 - high IL6

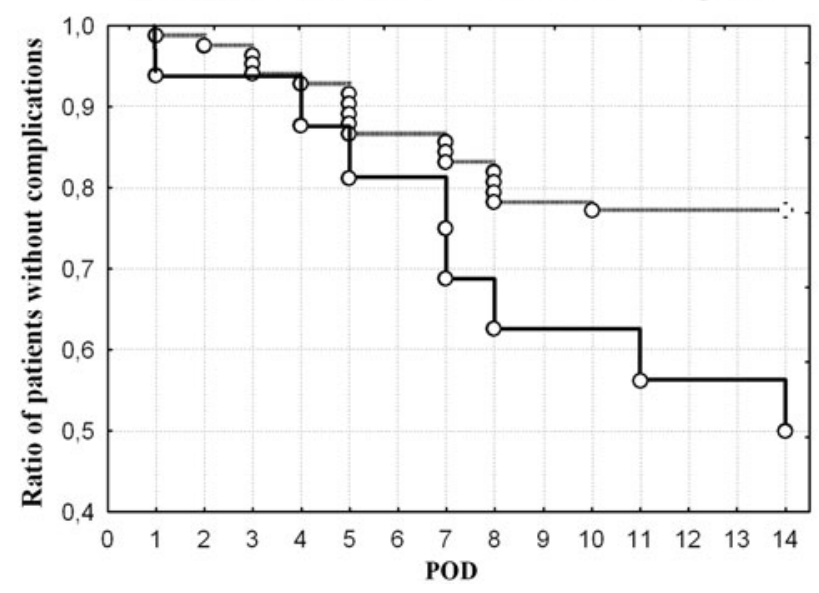

Fig. 1 Cumulative proportion of patients without complications within 14 days post-surgery. IL6 Interleukin $6, P O D$ postoperative day confounding variables, was performed. Risk estimates for overall complications and infective complications were similar to those observed in the previous analyses (Tables 3,4).

\section{Discussion}

Postoperative morbidity in gastric cancer remains high despite progress in perioperative care and surgical techniques. Gastrectomy for the treatment of gastric cancer is still one of the major procedures in general surgery and a 30 day postoperative complication rate of $20-40 \%$ has been reported [12-16]. In our study $28.3 \%$ of the patients had major or minor postoperative complications and the postoperative case-fatality rate was $3.03 \%$. Infections were the most frequent complication (observed in 24 patients), which was in line with other studies $[3,17]$. However, in the number of infections reported, some authors included anastomotic leakage and pancreatic fistulas, as they were considered the background for secondary infections [18]. Direct comparison of different studies was not always possible because complication types and data collection were not uniform [18-20]. The main risk factors reported in the literature are: the extent of lymphadenectomy, splenectomy, tumor size, age, comorbidities, American Society of Anesthesiologists (ASA) score, malnutrition, and preoperative blood loss [1, 12, 13, 16, 17, 21-23].

Some biochemical measures have also been reported as predictors of postoperative morbidity. Low serum albumin and low hemoglobin were reported as negative prognostic factors for morbidity [2, 22, 23]. These factors reflect malnutrition or the need for perioperative blood transfusions. Increased concentrations of C-reactive protein (CRP) and procalcitonin corresponded with the risk of postoperative infective complications, especially pneumonia [24]. There is also evidence that elevated pre- or postoperative levels of cytokines, especially IL-6, may be a prognostic factor for morbidity in various surgical procedures and diseases [25-28]. This cytokine is produced rapidly after surgical trauma and the blood level increases in the hours post-surgery [11]. On the other hand elevated preoperative IL-6 levels were observed in patients with more advanced disease [29]. Other cytokines were sporadically reported as being associated with the risk of postoperative morbidity.

A postoperative increase in IL-6 was reported in several studies after stomach resection for gastric cancer [30, 31]; however, its influence on morbidity was not analyzed. In assessing the complications of liver surgery, liver transplantation, and cardiothoracic surgery, increased IL-6 levels were indicated as a prognostic factor [25-27].

The postoperative testing of cytokines as well as other markers seems more rational than preoperative testing of cytokines concentrations, because the result depends on 
Table 3 Risk of overall complications

\begin{tabular}{|c|c|c|c|c|c|}
\hline IL-6 & $\begin{array}{l}\text { Person-day } \\
\text { (observation) }\end{array}$ & $\begin{array}{l}\text { No. of events/ } \\
\text { No. of patients }\end{array}$ & $\begin{array}{l}\text { Risk of } \\
\text { complications (HR) }\end{array}$ & $95 \% \mathrm{CI}$ & $p$ \\
\hline Overall complications ${ }^{\mathrm{a}}$ & 1169 & & & & \\
\hline$\leq 278.88 \mathrm{pg} / \mathrm{ml}$ & & $19 / 83(22.9 \%)$ & 1 & & \\
\hline$>278.88 \mathrm{pg} / \mathrm{ml}$ & & $8 / 16(50.0 \%)$ & 2.40 & $1.05-5.48$ & 0.038 \\
\hline Overall complications ${ }^{\mathrm{b}}$ & 1046 & & & & \\
\hline$\leq 278.88 \mathrm{pg} / \mathrm{ml}$ & & $16 / 74(21.6 \%)$ & 1 & & \\
\hline$>278.88 \mathrm{pg} / \mathrm{ml}$ & & $7 / 14(50.0 \%)$ & 2.79 & $1.01-7.76$ & 0.049 \\
\hline Overall complications ${ }^{\mathrm{c}}$ & 1046 & & & & \\
\hline$\leq 278.88 \mathrm{pg} / \mathrm{ml}$ & & $16 / 74(21.6 \%)$ & 1 & & \\
\hline$>278.88 \mathrm{pg} / \mathrm{ml}$ & & $7 / 14(50.0 \%)$ & 3.08 & $1.07-8.88$ & 0.038 \\
\hline Overall complications ${ }^{\mathrm{d}}$ & 1046 & & & & \\
\hline$\leq 278.88 \mathrm{pg} / \mathrm{ml}$ & & $16 / 74(21.6 \%)$ & 1 & & \\
\hline$>278.88 \mathrm{pg} / \mathrm{ml}$ & & $7 / 14(50.0 \%)$ & 3.57 & $1.15-11.10$ & 0.028 \\
\hline
\end{tabular}

$I L-6$ interleukin 6, HR hazard ratio, $C I$ confidence interval

${ }^{a}$ Univariate Cox proportional hazard model

b Multivariate Cox proportional hazard model; adjusted for age ( $\leq 50,51-60,61-70,>70)$, stage (I-IV), Lauren's type, type of surgery (total or partial resection), nutritional status (evaluated by total albumin level [cutoff $<3.5 \mathrm{~g} / \mathrm{dl}$ ] and total lymphocyte count [cutoff $<1500 / \mathrm{mm}^{3}$ ]), weight loss (in $\mathrm{kg}$ ), and reported time of weight loss (in months)

${ }^{c}$ Multivariate Cox proportional hazard model; adjusted for age ( $\left.\leq 50,51-60,61-70,>70\right)$, stage (I-IV), Lauren's type, type of surgery (total or partial resection), nutritional status (evaluated by total albumin level [cutoff $<3.5 \mathrm{~g} / \mathrm{dl}$ ] and total lymphocyte count [cutoff $<1500 / \mathrm{mm}^{3}$ ]), weight loss (in $\mathrm{kg}$ ), and reported time of weight loss (in months), diagnosis of cardiovascular disease (yes/no), diagnosis of pulmonary disease (yes/no), diagnosis of diabetes (yes/no), and diagnosis of any other disease (yes/no)

${ }^{\mathrm{d}}$ Multivariate Cox proportional hazard model; adjusted for age ( $\left.\leq 50,51-60,61-70,>70\right)$, stage (I-IV), Lauren's type, type of surgery (total or partial resection), nutritional status (evaluated by total albumin level [cutoff $<3.5 \mathrm{~g} / \mathrm{dl}$ ] and total lymphocyte count [cutoff $<1500 / \mathrm{mm}^{3}$ ]), weight loss (in $\mathrm{kg}$ ), and reported time of weight loss (in months), diagnosis of cardiovascular disease (yes/no), diagnosis of pulmonary disease (yes/no), diagnosis of diabetes (yes/no), diagnosis of any other disease (yes/no), and resection radicality (R0, R1, R2)

\section{Cumulative proportion of patients without infective complications}

(Kaplan - Meyer plots; log rank test $\mathrm{p}=0.039$ )

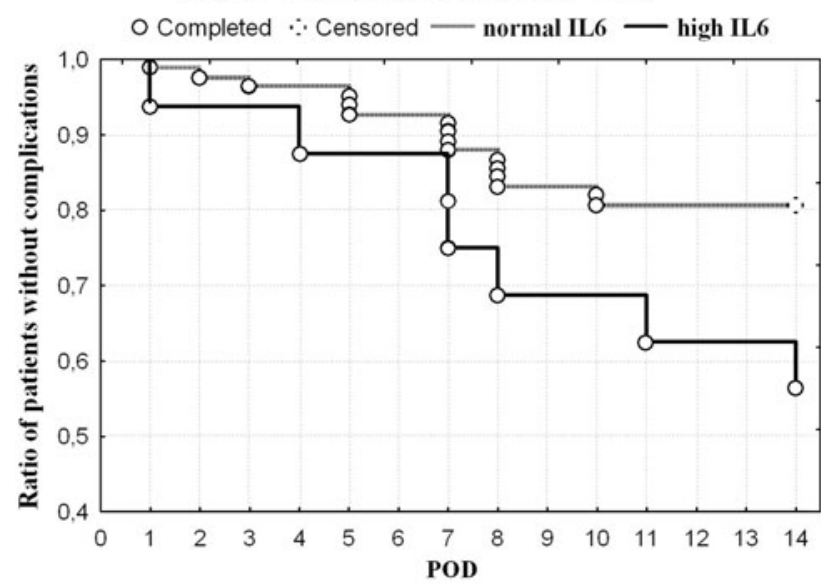

Fig. 2 Cumulative proportion of patients without infective complications within 14 days post-surgery

both tumor-related and patient-related factors and surgery. The marker should identify patients with an increased mortality and morbidity risk very early and thus enable close monitoring, additional diagnostic procedures and preventive measures, and early treatment of complications that do arise. Therefore, we investigated IL-6 levels on the first postoperative day (POD). Patients with "high" IL-6 levels had significantly higher complication rates. The univariate analysis calculated the hazard ratio (HR) of overall complications at 2.4 and that of infective complications at 2.51. Both estimates were statistically significant.

In the Cox proportional hazard model we used covariates (age, stage, Lauren's type, type of surgery performed, total albumin level, total lymphocyte count, weight loss, and the time of weight loss) that might influence postoperative morbidity [21-23]. Finally, the results of our study showed that a "high" IL-6 level might be an independent prognostic factor for overall $(\mathrm{HR}=2.79)$ and infective $(\mathrm{HR}=3.07)$ complications among stomach cancer patients. When comorbidities and resection radicality were added to the regression model, the HRs were 3.08 and 3.57, respectively, both with statistical significance.

Our study also has some limitations. IL-6 as a marker of inflammation was observed to be higher among patients with more advanced disease. The stage of cancer was a weak predictor of the level of IL-6 in our study and the correlation coefficient observed for these two variables was only 0.15 . The small sample size prevented us from 
Table 4 Risk of infective complications

\begin{tabular}{|c|c|c|c|c|c|}
\hline IL-6 & $\begin{array}{l}\text { Person-day } \\
\text { (observation) }\end{array}$ & $\begin{array}{l}\text { No. of events/ } \\
\text { No. of patients }\end{array}$ & $\begin{array}{l}\text { Risk of } \\
\text { complications (HR) }\end{array}$ & $95 \% \mathrm{CI}$ & $p$ \\
\hline Infective complications ${ }^{\mathrm{a}}$ & 1217 & & & & \\
\hline$\leq 278.88 \mathrm{pg} / \mathrm{ml}$ & & $16 / 83(19.3 \%)$ & 1 & & \\
\hline$>278.88 \mathrm{pg} / \mathrm{ml}$ & & $7 / 16(43.8 \%)$ & 2.51 & $1.03-6.11$ & 0.042 \\
\hline Infective complications ${ }^{\mathrm{b}}$ & 1076 & & & & \\
\hline$\leq 278.88 \mathrm{pg} / \mathrm{ml}$ & & $14 / 74(18.9 \%)$ & 1 & & \\
\hline$>278.88 \mathrm{pg} / \mathrm{ml}$ & & $7 / 14(50.0 \%)$ & 3.07 & $1.11-8.43$ & 0.030 \\
\hline Infective complications ${ }^{c}$ & 1076 & & & & \\
\hline$\leq 278.88 \mathrm{pg} / \mathrm{ml}$ & & $14 / 74(18.9 \%)$ & 1 & & \\
\hline$>278.88 \mathrm{pg} / \mathrm{ml}$ & & $7 / 14(50.0 \%)$ & 3.61 & $1.23-10.60$ & 0.020 \\
\hline Infective complications ${ }^{\mathrm{d}}$ & 1076 & & & & \\
\hline$\leq 278.88 \mathrm{pg} / \mathrm{ml}$ & & $14 / 74(18.9 \%)$ & 1 & & \\
\hline$>278.88 \mathrm{pg} / \mathrm{ml}$ & & $7 / 14(50.0 \%)$ & 4.35 & $1.36-13.97$ & 0.013 \\
\hline \multicolumn{6}{|c|}{${ }^{a}$ Univariate Cox proportional hazard model } \\
\hline \multicolumn{6}{|c|}{$\begin{array}{l}\text { b Multivariate Cox proportional hazard model; adjusted for age }(\leq 50,51-60,61-70,>70) \text {, stage (I-IV), Lauren's type, type of surgery (total or } \\
\text { partial resection), nutritional status (evaluated by total albumin level [cutoff }<3.5 \mathrm{~g} / \mathrm{dl} \text { ] and total lymphocyte count }\left[\mathrm{cutoff}<1500 / \mathrm{mm}^{3}\right] \text { ), weight } \\
\text { loss (in } \mathrm{kg} \text { ), and reported time of weight loss (in months) }\end{array}$} \\
\hline \multicolumn{6}{|c|}{$\begin{array}{l}\text { ' Multivariate Cox proportional hazard model; adjusted for age ( } \leq 50,51-60,61-70,>70) \text {, stage (I-IV), Lauren's type, type of surgery (total or } \\
\left.\left.\text { partial resection), nutritional status (evaluated by total albumin level [cutoff }<3.5 \mathrm{~g} / \mathrm{dl} \text { ), total lymphocyte count [cutoff }<1500 / \mathrm{mm}^{3}\right]\right), \text { weight loss } \\
\text { (in } \mathrm{kg} \text { ) and reported time of weight loss (in months), diagnosis of cardiovascular disease (yes/no), diagnosis of pulmonary disease (yes/no), } \\
\text { diagnosis of diabetes (yes/no), and diagnosis of any other disease (yes/no) }\end{array}$} \\
\hline \multicolumn{6}{|c|}{$\begin{array}{l}\text { d Multivariate Cox proportional hazard model; adjusted for age }(\leq 50,51-60,61-70,>70) \text {, stage (I-IV), Lauren's type, type of surgery (total or } \\
\text { partial resection), nutritional status (evaluated by total albumin level [cutoff }<3.5 \mathrm{~g} / \mathrm{dl}] \text { and total lymphocyte count }\left[\mathrm{cutoff}<1500 / \mathrm{mm}^{3}\right] \text { ), weight } \\
\text { loss (in } \mathrm{kg} \text { ) and reported time of weight loss (in months), diagnosis of cardiovascular disease (yes/no), diagnosis of pulmonary disease (yes/no), } \\
\text { diagnosis of diabetes (yes/no), diagnosis of any other disease (yes/no), and resection radicality (R0, R1, R2) }\end{array}$} \\
\hline
\end{tabular}

performing reliable analysis in the subgroups of stage; however, stage, Lauren's type, and type of surgery were put in the multivariate proportional Cox model as potential confounders.

A proportion of our patient group underwent palliative surgery. Among these patients the risk of developing complications is higher [32]. Resection radicality was also included in the multivariate analysis. It is still under question whether the same effect of the high 1st POD IL-6 level on the risk of development of post-surgery complications may be expected for patients with different $\mathrm{R}$ scores; however, to reveal the answer to this question, more investigations with large sample sizes are required.

The available data on the possible cutoff for the IL-6 level as a predictor of complications among patients after stomach cancer surgery are very sparse. In our study we decided to use the 90th percentile as the threshold; however, this value characterizes our sample only. More investigations are needed to evaluate how the proposed cutoff might be a good predictor of postsurgical complications for other groups of stomach cancer patients.

It is not clear whether the "high" IL-6 level is metabolic or whether it is due to an individual property of patients' immune cells involved in the production of increased amounts of IL-6. Some investigational data show that IL-6 gene polymorphism may influence IL-6 serum levels in vivo $[33,34]$. This may result in a high level of IL-6 production that is genetically determined. However, in a series of cardiosurgery patients this relationship was not observed [35]. Of note, immunomodulatory strategies have been adopted to change postoperative cytokine production and decrease inflammatory reactions, to influence morbidity [36, 37]. These reports describe a limited series of patients and no large clinical trial in this field has been published.

\section{Conclusion}

Our study showed an association between perioperative IL-6 serum levels and postoperative morbidity in gastric cancer patients. The first POD IL-6 serum level was shown to be an independent prognostic factor for both overall complications and infective complications. Therefore, the results of our study show that the IL- 6 serum level could be used as an early prognostic. The current data on the association of the IL-6 serum level with postoperative morbidity among stomach cancer patients are very limited, and 
more investigations are required to set up the threshold level. IL-6 levels need to be evaluated prospectively in an independent group of patients. Moreover, further investigation of the pathogenesis of high IL- 6 production and possible strategies to prevent complications are needed.

Acknowledgments This work was supported by the Ministry of Science and Higher Education of Poland grant 2P05C 00129.

Open Access This article is distributed under the terms of the Creative Commons Attribution Noncommercial License which permits any noncommercial use, distribution, and reproduction in any medium, provided the original author(s) and source are credited.

\section{References}

1. Persiani R, Antonacci V, Biondi A, Rausei S, La Greca A, Zoccali $\mathrm{M}$, et al. Determinants of surgical morbidity in gastric cancer treatment. J Am Coll Surg. 2008;207:13-9.

2. Nagabhushan JS, Srinath S, Weir F, Angerson WJ, Sugden BA, Morran CG. Comparison of P-POSSUM and O-POSSUM in predicting mortality after oesophagogastric resections. Postgrad Med J. 2007;83:355-8.

3. Sah BK, Zhu ZG, Chen MM, Yan M, Yin HR, Zhen LY. Gastric cancer surgery and its hazards: post operative infection is the most important complication. Hepatogastroenterology. 2008;55: 2259-63.

4. Dhingra R, Gona P, Nam BH, D'Agostino RB Sr, Wilson PW, Benjamin EJ, et al. C-reactive protein, inflammatory conditions, and cardiovascular disease risk. Am J Med. 2007;120:1054-62.

5. Ramadori G, Christ B. Cytokines and the hepatic acute-phase response. Semin Liver Dis. 1999;19:141-55.

6. Moshage HJ, Janssen JA, Franssen JH, Hafkenscheid JC, Yap SH. Study of the molecular mechanisms of decreased liver synthesis of albumin in inflammation. J Clin Invest. 1987;79: 1635-41.

7. Goldbach JM, Roth J, Zeisberger E. Fever suppression by subdiaphragmatic vagotomy in guinea pigs depends on the route of pyrogen administration. Am J Physiol. 1997;272:R675-81.

8. Chrousos GP. The hypothalamic-pituitary-adrenal axis and immune-mediated inflammation. N Engl J Med. 1995;332: 1351-62.

9. Means RT Jr. Pathogenesis of the anemia of chronic disease: a cytokine-mediated anemia. Stem Cells. 1995;13:32-7.

10. Wen XH, Kong HY, Zhu SM, Xu JH, Huang SQ, Chen QL. Plasma levels of tumor necrotic factor-alpha and interleukin-6, -8 during orthotopic liver transplantation and their relations to postoperative pulmonary complications. Hepatobiliary Pancreat Dis Int. 2004;3:38-41.

11. Kragsbjerg P, Holmberg H, Vikerfors T. Serum concentrations of interleukin-6, tumour necrosis factor-alpha, and C-reactive protein in patients undergoing major operations. Eur J Surg. 1995;161:17-22.

12. Schwarz RE, Zagala-Nevarez K. Gastrectomy circumstances that influence early postoperative outcome. Hepatogastroenterology. 2002;49:1742-6.

13. Kulig J, Popiela T, Kolodziejczyk P, Sierzega M, Szczepanik A, Polish Gastric Cancer Study Group. Standard D2 versus extended D2 (D2+) lymphadenectomy for gastric cancer: an interim safety analysis of a multicenter, randomized, clinical trial. Am J Surg. 2007;193:10-5.
14. Yonemura Y, Wu CC, Fukushima N, Honda I, Bandou E, Kawamura $\mathrm{T}$, et al. Operative morbidity and mortality after D2 and D4 extended dissection for advanced gastric cancer: a prospective randomized trial conducted by Asian surgeons. Hepatogastroenterology. 2006;53:389-94.

15. Pedrazzani C, Marrelli D, Rampone B, De Stefano A, Corso G, Fotia G, et al. Postoperative complications and functional results after subtotal gastrectomy with Billroth II reconstruction for primary gastric cancer. Dig Dis Sci. 2007;52:1757-63.

16. Orsenigo E, Tomajer V, Palo SD, Carlucci M, Vignali A, Tamburini A, et al. Impact of age on postoperative outcomes in 1118 gastric cancer patients undergoing surgical treatment. Gastric Cancer. 2007;10:39-44.

17. Mohri Y, Tonouchi H, Miki C, Kobayashi M, Kusunoki M, Mie Surgical Infection Research Group. Incidence and risk factors for hospital-acquired pneumonia after surgery for gastric cancer: results of prospective surveillance. World J Surg. 2008;32: $1045-50$

18. Tsujimoto H, Ichikura $\mathrm{T}$, Ono $\mathrm{S}$, Sugasawa H, Hiraki S, Sakamoto N, et al. Impact of postoperative infection on long-term survival after potentially curative resection for gastric cancer. Ann Surg Oncol. 2009;16:311-8.

19. Tonouchi H, Ohmori Y, Tanaka K, Mohri Y, Kobayashi M, Kusunoki M. Fatal and non-fatal complications after surgical resection for gastric cancer. Hepatogastroenterology. 2006;53: 145-9.

20. Sah BK, Chen MM, Yan M, Zhu ZG. Reoperation for early postoperative complications after gastric cancer surgery in a Chinese hospital. World J Gastroenterol. 2010;16:98-103.

21. Onodera H, Tokunaga A, Yoshiyuki T, Kiyama T, Kato S, Matsukura N, et al. Surgical outcome of 483 patients with early gastric cancer: prognosis, postoperative morbidity and mortality, and gastric remnant cancer. Hepatogastroenterology. 2004;51: $82-5$.

22. Bozzetti F, Gianotti L, Braga M, Di Carlo V, Mariani L. Postoperative complications in gastrointestinal cancer patients: the joint role of the nutritional status and the nutritional support. Clin Nutr. 2007;26:698-709.

23. Marrelli D, Pedrazzani C, Neri A, Corso G, DeStefano A, Pinto E, et al. Complications after extended (D2) and superextended (D3) lymphadenectomy for gastric cancer: analysis of potential risk factors. Ann Surg Oncol. 2007;14:25-33.

24. Montagnana M, Minicozzi AM, Salvagno GL, Danese E, Cordiano C, De Manzoni G, et al. Postoperative variation of $\mathrm{C}$-reactive protein and procalcitonin in patients with gastrointestinal cancer. Clin Lab. 2009;55:187-92.

25. Musleh GS, Datta SS, Yonan NN, Grotte GJ, Prendergast BA, Hasan RI, et al. Association of IL6 and IL10 with renal dysfunction and the use of haemofiltration during cardiopulmonary bypass. Eur J Cardiothorac Surg. 2009;35:511-4.

26. Hoksch B, Fahrner R, Alexander Schmid R. Procalcitonin and brain natriuretic peptide as parameters in the postoperative course of patients with major pulmonary resection. Interact Cardiovasc Thorac Surg. 2007;6:155-9.

27. Kimura F, Shimizu H, Yoshidome H, Ohtsuka M, Kato A, Yoshitomi H, et al. Increased plasma levels of IL-6 and IL-8 are associated with surgical site infection after pancreaticoduodenectomy. Pancreas. 2006;32:178-85.

28. Kimura F, Shimizu H, Yoshidome H, Ohtsuka M, Kato A, Yoshitomi H, et al. Circulating cytokines, chemokines, and stress hormones are increased in patients with organ dysfunction following liver resection. J Surg Res. 2006;133:102-12.

29. Ikeguchi M, Hatada T, Yamamoto M, Miyake T, Matsunaga T, Fukumoto Y, et al. Serum interleukin-6 and -10 levels in patients with gastric cancer. Gastric Cancer. 2009;12:95-100. 
30. Kim DK, Oh SY, Kwon HC, Lee S, Kwon KA, Kim BG, et al. Clinical significances of preoperative serum interleukin-6, C-reactive protein level in operable gastric cancer. BMC Cancer. 2009;9:155.

31. Kishimoto K, Hiraguri M, Koide N, Hanazaki K, Adachi W. Postoperative suppression of inflammatory cytokines after distal gastrectomy in elderly patients. Surg Today. 2009;39:487-92.

32. Kotan C, Kisli E, Sönmez R, Cikman O, Arslan M, Arslanturk H, Soylemez O, Başer M. Noncurative total gastrectomy and oesophagogastrectomy in the treatment of advanced gastric carcinoma in a country with high incidence. Acta Chir Belg. 2005;105: 519-22.

33. Arranz Duran J, Arteaga González A, Domínguez García D, Calvo Falcón R, Flores C, González-Paredes FJ. Polymorphisms of interleukin-6 and tumor necrosis factor gene promoters and cardiorespiratory function following liver transplantation: a preliminary study. Transplant Proc. 2009;41:1062-4.
34. Bennermo M, Held C, Stemme S, Ericsson CG, Silveira A, Green F, Tornvall P. Genetic predisposition of the interleukin-6 response to inflammation: implications for a variety of major diseases? Clin Chem. 2004;50(11):2136-40.

35. Sanders J, Hawe E, Brull DJ, Hubbart C, Lowe GD, Rumley A, et al. Higher IL-6 levels but not IL6-174G $>$ C or $-572 \mathrm{G}>\mathrm{C}$ genotype are associated with post-operative complication following coronary artery bypass graft (CABG) surgery. Atherosclerosis. 2009;204:196-201.

36. Park JH, Kwak SH, Jeong CW, Bae HB, Kim SJ. Effect of ulinastatin on cytokine reaction during gastrectomy. Korean $\mathrm{J}$ Anesthesiol. 2010;58:334-7.

37. Okamoto $\mathrm{Y}$, Okano $\mathrm{K}$, Izuishi $\mathrm{K}$, Usuki $\mathrm{H}$, Wakabayashi $\mathrm{H}$, Suzuki Y. Attenuation of the systemic inflammatory response and infectious complications after gastrectomy with preoperative oral arginine and omega-3 fatty acids supplemented immunonutrition. World J Surg. 2009;33:1815-21. 